\title{
Multivessel Thromboembolism Associated with Dysfunction of Protein S
}

\author{
Eun Jae Ok, M.D., Hye Won Kim, M.D., Sang Dong Kim, M.D. ${ }^{1}$, Kyoung Soo Park, M.D., \\ Yang Soo Kim, M.D., Ha Min Kim, M.D., Seong Hoon Lim, M.D.
}

Departments of Rehabilitation Medicine, ' Surgery, College of Medicine, The Catholic University of Korea, Suwon 442-723, Korea

Protein S is a vitamin K-dependent coagulation factor that acts as an anticoagulant. Deficiency of protein S increases the risk of thromboembolic events. We report a case of isolated protein S deficiency in a 39-year-old woman suffering arterial occlusion in both lower legs. She underwent a surgical procedure using thrombectomy and balloon angioplasty of her left lower extremity. Later, she had right trans-tibial amputation because of the reperfusion injury. Throughout the evaluation of thromboembolic events, we diagnosed a large thrombus in the right atrium and an asymptomatic pulmonary thromboembolism. The patient was successfully treated with right atrial thrombectomy and systemic anticoagulation. Careful evaluation for protein S levels may be necessary in patients with arterial thromboembolic events, especially young adults.

Key Words Protein S, Thromboembolism, Trans-tibial amputation

\section{INTRODUCTION}

Various genetic risk factors are known to be responsible for recurrent venous and arterial thromboembolisms. Among the risk factors, protein $\mathrm{S}$ is a plasma protein that functions as a cofactor for the anticoagulant activity of protein C. Deficiency of protein S may result in recurrent episodes of coagulopathy, including superficial, deep

Received February 18, 2011; Accepted July 12, 2011

Corresponding author: Seong Hoon Lim

Department of Physical Medicine and Rehabilitation, St. Vincent Hospital, College of Medicine, The Catholic University of Korea, 93-6, Jidong, Suwon 442-723, Korea

Tel: +82-31-249-7650, Fax: +82-31-251-4481,E-mail: seonghoon@ catholic.ac.kr

(c) This is an open-access article distributed under the terms of the Creative Commons Attribution Non-Commercial License (http:// creativecommons.org/licenses/by-nc/3.0) which permits unrestricted noncommercial use, distribution, and reproduction in any medium, provided the original work is properly cited.

Copyright () 2012 by Korean Academy of Rehabilitation Medicine vein thrombosis, and pulmonary emboli. The true prevalence of protein S deficiency is unknown as not all individuals develop thrombosis. Some studies have indicated a frequency of $2-8 \%$ in patients with deep vein thrombosis or pulmonary embolism and it is reported that patients with protein S deficiency have a chance of developing recurrent thrombosis before age $45{ }^{1,2}$ Among the patients with thrombosis, exclusive deficiency of protein $S$ is rare, and only 1 case of multiple arterial thrombosis associated with decreased protein S activity (43\%) has been reported in the country. ${ }^{3}$

This case report is an instance of protein S deficiency diagnosed in the course of elucidating the cause of occlusions in the lower extremities of the patient, who had management of below-knee amputation and incidentally presented right atrial and pulmonary arterial thrombosis throughout investigations. 


\section{CASE REPORT}

A previously healthy 39-year old woman presented to the emergency department with 4 days of painful swelling and discoloration of her right lower leg, and gangrenous change of her right toe tips (Fig. 1). The patient had no history of hypertension, diabetes, dyslipidemia, trauma or illicit use of drugs, including oral contraceptives, but had used tobacco for 10 years.

The patient had been suffering from pain and swelling in her right lower leg for 4 days and on arrival in the hospital, initial physical examination showed a gangrenous change of her entire foot and toes below the right metatarsals, and her calf appeared to be pale with pain, paresthesia and cold sensation. Laboratory investigation showed a platelet count of $37,000 / \mathrm{mm}^{3}$. Due to suspicion of arterial thrombosis, computed tomography (CT) of arteries of the lower extremities was conducted and it demonstrated diffuse vascular occlusion by thrombus in the right infra-renal aorta through the popliteal artery and also left superficial femoral artery (Fig. 2). The patient underwent emergency thrombectomy, and immediate infusion of 50,000 IU of urokinase in both lower legs through a catheter and balloon angioplasty of the left superficial femoral artery. Following the operation, reperfusion injury developed that advanced erythematous edema and necrosis which necessitated below-knee amputation. The patient transferred to the Department of Rehabilitation Medicine and began stump

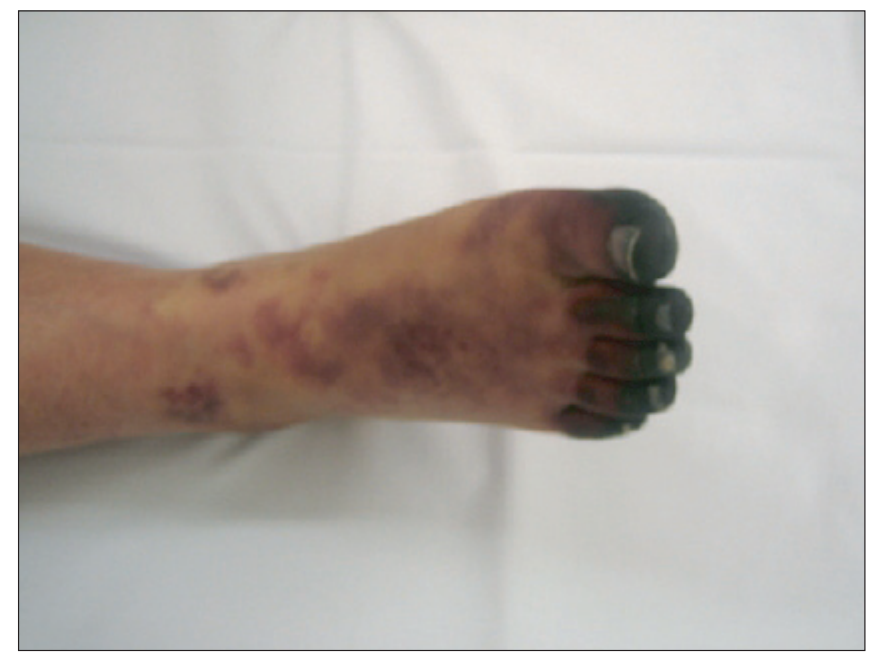

Fig. 1. On the day of arrival in the hospital, pedal gangrenous change and ischemia had progressed to the distal third of the right leg and whole foot. care for its maturation and had started a comprehensive rehabilitation program with a patellar-tendon bearing below-knee prosthesis (PTBS). She was prescribed an oral anticoagulant (warfarin) to prevent recurrences of arterial thrombosis through maintaining an International normalized ratio (INR) of 2-3.

Detailed laboratory investigations were done to identify the cause of multiple arterial thromboses. The aCL (anticardiolipin antibody), aPA (anti-phospholipid antibody), antithrombin III, platelet aggregation test, VDRL (venereal disease research laboratory microflocculation), LA (lupus anticoagulant), ANCA (antineutrophil cytoplasmic antibody), serum complement C3/C4 level, homocysteine $(11.04 \mu \mathrm{mol} / \mathrm{L})$, bone marrow biopsy, chromosome test and coagulation factor V, VIII, IX and $\mathrm{XI}$ were in normal ranges and did not appear to be the reason for thrombosis. Serum C protein showed an antigen level of $51.70 \%$ (normal: $72-160 \%$ ) and activity of $63 \%$ (normal: $70-130 \%$ ), which were lightly decreased at the initial exam, but a followup showed normal activity of 89\%. Otherwise, protein S demonstrated a total level of $57.40 \%$ (normal: $60-150 \%$ ), and activity of $0.2 \%$ (normal: 73.7-146.3\%) which were the only remarkably decreased factors throughout the followup laboratory investigations. Thereupon, authors diagnosed the cause of multiple arterial thromboses as decreased protein S activity.

Considering possibilities of multiple thrombosis in other organs, transthoracic and transesophageal

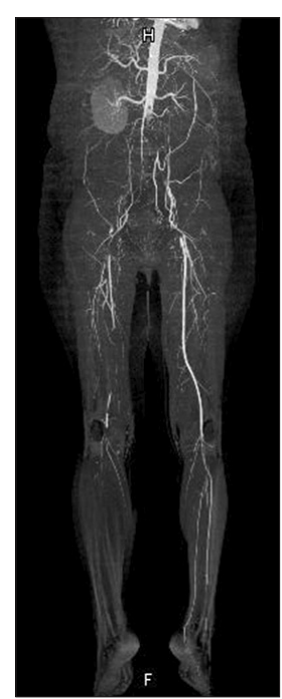

Fig. 2. Lower extremity 3D CT showed occlusions in right superficial femoral, popliteal arteries and total occlusion below the knee. 

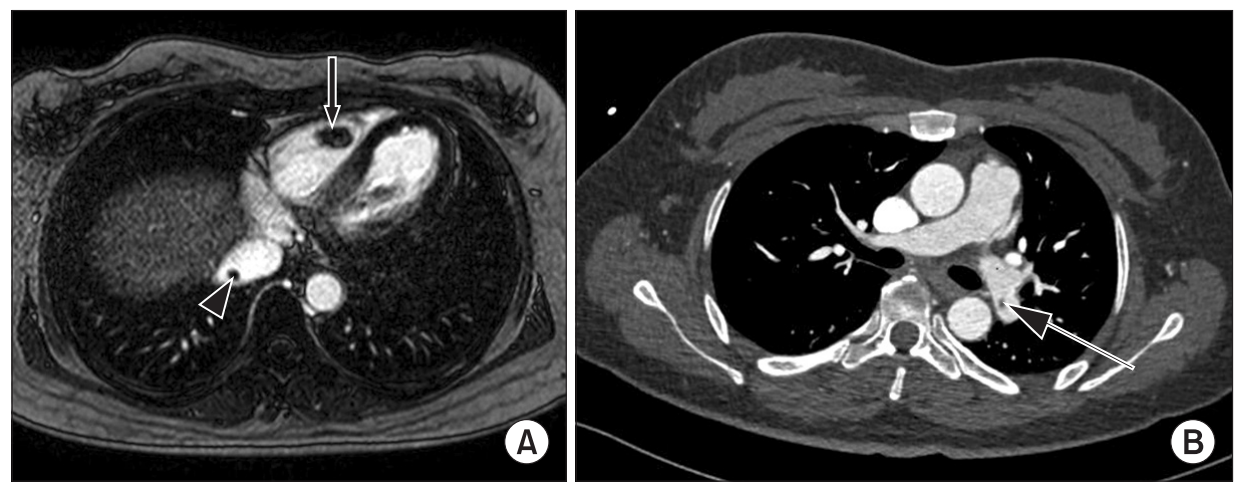

Fig. 3. (A) Heart MRI showed a calcified thrombi in apex of the right ventricle (arrow) and in IVC (arrowhead), near the atriocaval junction. (B) Coronary artery CT showed low density thromboses in proximal left inferior pulmonary artery.

echocardiograms were conducted, which surprisingly showed a $3.33 \times 1.22 \mathrm{~cm}$ sized mass. Magnetic resonance imaging (MRI) of the heart and coronary angiographic CT revealed thrombus in the right atrium and inferior vena cava (IVC) and thromboembolism involving both segmental and subsegmental branches of the pulmonary artery (Fig. 3). The patient underwent surgery to remove the right atrial thrombus with pathologic confirmation. After the operation, she continued taking oral warfarin to prevent recurrent thromboembolism and also aggressive rehabilitation with her prosthesis.

\section{DISCUSSION}

Acute arterial occlusions in lower limbs are typically the result of atrial fibrillation, myocardial infarction, thrombus and embolus formed in valvular heart diseases, decreased perfusion of peripheral arteries, and other hypercoagulable states. When arterial occlusion occurs, pathognomonic 5P's signs (which stand for pain, polar, pulseless, paresthesia and paralysis) appear, just like the patient in this case showed at initial physical examination. It is a principle of management to conduct amputation if ischemic necrosis already developed.

The patient also presented right atrial thrombus in her heart. The most common underlying pathologic predisposition to atrial thrombus is atrial dilatation, decreased cardiac output, intracardiac catheter insertion, peripheral deep vein thromboembolism and other generalized conditions such as a malignant tumor, amyloidosis and nephritic syndrome. ${ }^{4}$ Right atrial thrombus is a rare condition commonly related to pulmonary embolism, which can be life threatening, and therefore requires an accurate diagnosis and immediate management. In this case report, the size of the atrial thrombus was relatively large and accompanied pulmonary thromboembolism, which means the thrombus was a secondary product. It has been reported that surgical treatment is more beneficial for the patient than single anticoagulation therapy, as in this case. ${ }^{5}$

Formation of multiple thromboses in arteries and organs means that a patient is in a hypercoagulable state. Few publications exist regarding arterial occlusion and protein $\mathrm{C}$ or $\mathrm{S}$ deficiencies. Protein $\mathrm{S}$ is a vitamin $\mathrm{K}$ dependent glycoprotein which acts as a cofactor for protein $\mathrm{C}$ and phospholipids to inactivate factors Va and VIIIa. The prevalence of protein $S$ deficiency in the general population is unknown but is $0.03-0.13 \%$ in Caucasians ${ }^{6}$; however, in patients with venous thrombosis, a frequency of $5 \%$ has been reported for S deficiency. ${ }^{2}$ As of yet, nothing has been reported regarding prevalence in South Korea. Protein S deficiency may be caused by congenital or secondary etiologies. Secondary deficiency can be caused by pregnancy, oral contraceptives, disseminated intravascular coagulation (DIC), liver failure, type 1 diabetes mellitus, nephritic syndrome, malignant tumors or autoimmune diseases, including lupus erythematosus. ${ }^{7}$ These conditions contribute to venous (of lower limbs, commonly) thromboembolism and less to pulmonary embolism. Arterial thrombosis associated with protein S deficiency is uncommon, and Broekmans and Conrad showed frequency of arterial thrombosis as $0.1 \%$ of that of venous thrombosis. ${ }^{8,9}$ In this case report, the patient had no specific disease or condition that incurred by protein S deficiency, and other laboratory findings were clear, except the activity of protein $S$ showed a marked decline to an almost inactivate state of $0.2 \%$ normal value.

In plasma, protein $S$ has two circulating forms: $60 \%$ exists as a covalent complex with the $\beta$-chain of the 
complement component $\mathrm{C} 4 \mathrm{~b}$ binding protein, while the remaining $40 \%$ unbound protein. This free protein $S$ functions in plasma as a cofactor to activate protein C2. ${ }^{9}$ Although total protein $S$ levels remained in the normal range, decreased free protein $S$ levels results in a hypercoagulable state. There are 3 types of protein deficiency: type I characterized by low total and free protein S antigen level; type II characterized by selective reduction in activity of protein S levels, and type III exhibits normal total protein $S$ levels with decreased free protein $S$ and decreased activity. ${ }^{10}$ The patient in the case report showed a nearly normal level of total protein $\mathrm{S}$ of $57.40 \%$ (normal: $60-150 \%$ ), but activity of protein S was selectively decreased to $0.2 \%$ of normal, which suggests the possibility of type II or type III deficiency. We could not clearly define the type of deficiency because the selective free protein $S$ level was not examined.

There are few instances of arterial thromboses associated with protein S deficiency in the thoracic aorta, the mesenteric, cerebral and renal arterial vascular beds, ${ }^{3}$ with a decreased activity of $43 \%$. No cases of multiple thromboembolisms in both arteries of lower limbs, heart and pulmonary arteries have been reported, but did occur in this case.

In summary, this case report suggests that young patients who present with thromboses and demonstrate no risk factors such as trauma, surgery, immobilization, obesity, smoking, hypertension, oral contraceptives, tumor, and stroke should be evaluated for hypercoagulable states, including protein $\mathrm{C}$ or protein $\mathrm{S}$ deficiency. Although protein $S$ deficiency has a low prevalence, its systemic relapsing thromboses can be fatal. It is required to examine protein $S$ levels when diagnosing thrombosis. Overall, we present a case of protein S deficiency with remarkably decreased activity, which resulted in multiple thromboembolisms and below-knee amputation.

\section{REFERENCES}

1. Nizzi FA Jr, Kaplan HS. Protein C and S deficiency. Semin Thromb Hemost 1999; 25: 265-272

2. Gladson CL, Scharrer I, Hach V, Beck KH, Griffin JH. The frequency of type I heterozygous protein $\mathrm{S}$ and protein $\mathrm{C}$ deficiency in 141 unrelated young patients with venous thrombosis. Thromb Haemost 1988; 59: 18-22

3. Kim TW, Kang GW, Hong HL, Mun SH, Lee IH, Ahn KS. A case of acute bilateral renal infarction associated with protein S deficiency. Korean J Nephrol 2010; 29: 617-622

4. Aoyagi S, Nishimi M, Hiratsuka R, Takaseya T, Teshima H. Right atrial thrombus associated with combined valvular disease: case report. J Heart Valve Dis 2001; 10: 542-544

5. Kronick G. The European Cooperative Study on the clinical significance of right heart thrombi. European Working Group on Echocardiography. Eur Heart J 1989; 10: 1046-1059

6. Dykes AC, Walker ID, McMahon AD, Islam SI, Tait RC. A study of Protein S antigen levels in 3788 healthy volunteers: influence of age, sex and hormone use, and estimate for prevalence of deficiency state. $\mathrm{Br} \mathrm{J}$ Haematol 2001; 113: 636-641

7. Cumming AM, Shiach CR. The investigation and management of inherited thrombophilia. Clin Lab Haematol 1999; 21: 77-92

8. Broekmans AW, Conrad J. Hereditary protein C deficiency. Contemp Issues Haemost Thromb 1988; 3: 160-181

9. Coller BS, Owen J, Jesty J, Horowitz D, Reitman MJ, Spear J, Yeh T, Comp PC. Deficiency of plasma protein $\mathrm{S}$, protein $\mathrm{C}$, or antithrombin III and arterial thrombosis. Arteriosclerosis 1987; 7: 456-462

10. Van Cott EM, Laposata M. Laboratory evaluation of hypercoaguable states. Hematol Oncol Clin North Am 1988; 12: 1141-1166 